\begin{tabular}{ll}
\hline \hline MINING AND METALLURGY INSTITUTE BOR & ISSN: 2334-8836 (Štampano izdanje) \\
UDK: 622 & ISSN: 2406-1395 (Online) \\
\hline \hline
\end{tabular}

Nenad Magdalinović, Bojan Drobnjaković, Ivana Jovanović, Sanja Petrović*

\title{
OPTIMAL NUMBER OF REVOLUTION THE ECCENTRIC SHAFT OF A JAW CRUSHER WITH A SIMPLE MOTION OF THE MOVING JAW
}

\begin{abstract}
The paper analyzes forces acting on a piece of raw material in a jaw crusher with a simple motion of the moving jaw, and based on this defines the formula to define the optimal number of revolutions the eccentric shaft. Under the optimum number of revolution the eccentric shaft, the number of revolutions is assumed to ensure that the crusher achieves the maximum crushing capacity.

Keywords: jaw crusher, capacity, optimum speed, shaft
\end{abstract}

\section{INTRODUCTION}

The most important technological feature of the jaw crushers is its capacity. The capacity depends on the number of revolutions of the eccentric shaft with a simple motion of the moving jaw. The crusher achieves the maximum capacity at the optimum speed of the eccentric shaft. The optimum speed of the eccentric shaft is the number of revolutions that ensures that the time of a half-revolution of the eccentric shaft $t_{2}$ is equal to the time $t_{1}$ required during the idling of the moving jaw, the crushed pieces fall the level BB1 through the working space for height $h$ to the level of discharge AA1(Fig.1).

In the theoretical considerations and derivation the formula for the optimal number of revolutions of the eccentric shaft, two different approaches are present in the literature. The first approach (Andreev, 1966) [1], based on the assumption that discharge of the crushed product from the workspace of the crusher, is carried out during an empty stroke and that the half-time of the eccentric shaft rotation must be equal to the free fall time of the crushed pieces from the level BB1 to the level AA1 of discharge opening (Fig.1). Starting from this assumption, the optimal number of rotations of the eccentric shaft is defined by the formula [1]:

$$
n_{o}=30 \cdot \sqrt{\frac{g \cdot \operatorname{tg} \propto}{2 \cdot e}}(\mathrm{Rpm})
$$

$\mathrm{n}_{\mathrm{o}}$ - optimum speed of the eccentric shaft, (Rpm)

$\mathrm{g}$ - acceleration due to gravity, $\left(\mathrm{m} / \mathrm{s}^{2}\right)$

$\alpha$ - crusher working angle, $\left({ }^{\circ}\right)$

e - movement of the moving jaw at the level of discharge opening, $(\mathrm{m})$

In carrying out the formula (1), the resistant force between the crusher jaws, when leaving the workspace of the crusher, were not taken into account. Therefore, in practice, the reduction in the number of turns, which is obtained according to the formula (1), is recommended for $5-10 \%$.

\footnotetext{
* Mining and Metallurgy Institute Bor, Zeleni bulevar 35, Bor, e-mail:nenad.magdalinovic@irmbor.co.rs
} 
Another approach (Magdalinović N, 1980/81)[2] is based on the assumption that the crushed products does not fall freely from the level of BB1 to the level at the discharge opening AA1, but during the discharge, the crushed product slides along the steep level B1A1 on the mobile jaw (Fig.1). According to this assumption, the optimal number of rotations of the eccentric shaft is defined by the formula [2]:

$$
n_{o}=30 \cdot \sqrt{\frac{g \cdot(\cos \alpha-f \cdot \sin \alpha) \cdot \sin \alpha}{2 \cdot e}}(\mathrm{Rpm})
$$

The first assumption (Andreev, 1966) at least reflects the reality of discharge the crushed products, since the pieces of crushed raw material do not fall freely through the workspace of the crusher

The second assumption (Magdalinović $\mathrm{N}, 1980 / 81$ ) is closer to the reality, but ignores the fact that when sliding the crushed products on the surface of the moving jaw, exist the friction force between the pieces and a fixed jaw $\mathrm{T}_{2}$ (Fig.2).

The aim of this paper is to include, in addition to the force of friction along the surface of the mobile jaw, the friction force between the pieces and surface of the fixed jaw, in the analysis of discharge the crushing product from the workspace of the crusher.

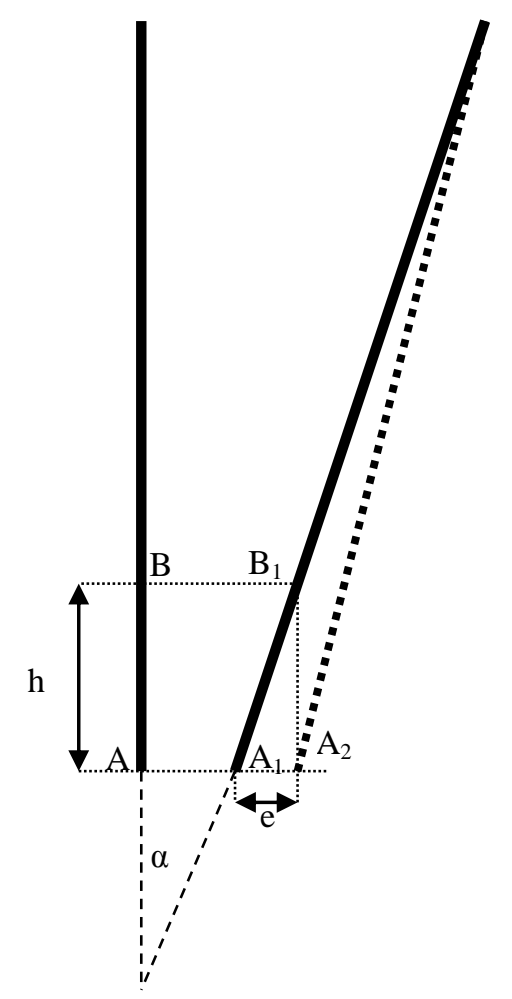

Fig. 1 Cross section of the workspace of the jaw crusher 


\section{Theoretical analysis}

In discharging the crushing product, the catch angle $\alpha$ is slightly increased, and this will be ignored in the analysis.

Sliding the pieces on a surface of the moving jaw plate (Fig. 2) opposes the friction force $\mathrm{T} 1$ :

$$
T_{1}=f \cdot N_{1}
$$

$\mathrm{f}$ - coefficient of friction the pieces on the surface of the movable and fixed jaw plate

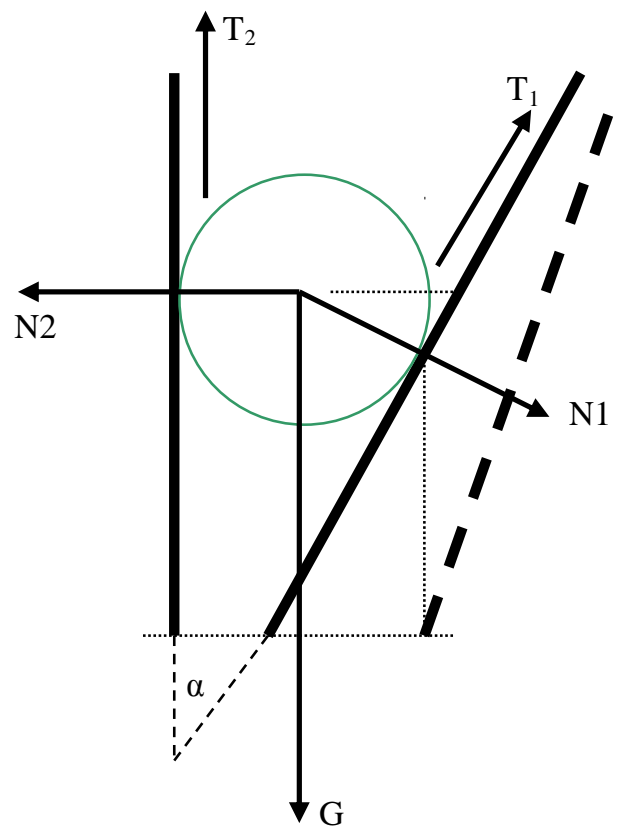

Fig. 2 Force acting on a piece when discharge from the workspace of crusher

When the crushing product discharge through the working area of the crusher, the friction force of the piece on the surface of the fixed jaw T2 (Fig.2) also exists:

$$
T_{2}=f \cdot N_{2}
$$

For discharging the pieces from the workspace of the crusher, the resultant $\mathrm{R}$ of all the forces acting on the piece in a vertical direction is a valid one:

$$
R=m \cdot a=G-T_{1} \cdot \cos \alpha-T_{2}
$$

From the conditions of equilibrium, the force follows:

$$
\begin{gathered}
\Sigma X_{i}=O \Longrightarrow-N_{2}+T_{1} \cdot \sin \alpha+ \\
+N_{1} \cos \alpha=0 \\
\Sigma Y_{i}=0 \Rightarrow T_{2}+T_{1} \cdot \cos \alpha- \\
-N_{1} \cdot \sin \alpha-m \cdot g=0
\end{gathered}
$$

Where, after solving the equations (6) and (7), the following values are obtained: 


$$
\begin{aligned}
& N_{1}=\frac{m \cdot g}{f \cdot(\cos \alpha-f \cdot \sin \alpha)+f \cdot \cos \alpha+\sin \alpha} \\
& N_{2}=\frac{m \cdot g \cdot(\cos \alpha-f \cdot \sin \alpha)}{f \cdot(\cos \alpha-f \cdot \sin \alpha)+f \cdot \cos \alpha+\sin \alpha}
\end{aligned}
$$

After replacing (8) and (9) in the equation (10), the expression is obtained:

$$
m \cdot a=m \cdot g-f \cdot N_{1} \cdot \cos \alpha-f N_{2}
$$

Where $a$ is the acceleration of pieces when discharge through the working space of the crusher

Acceleration $a$ can be expressed by the first derivative of the velocity $v$ by time $t$, and the equation (10) takes the form:

$$
\frac{d v}{d t}=g \cdot\left(1-\frac{f \cdot(2-f \cdot \operatorname{tg} \alpha)}{f \cdot(2-f \cdot \operatorname{tg} \alpha)+\operatorname{tg} \alpha}\right)
$$

respectively:

$$
d v=g \cdot\left(1-\frac{f \cdot(2-f \cdot \operatorname{tg} \alpha)}{f \cdot(2-f \cdot \operatorname{tg} \alpha)+\operatorname{tg} \alpha}\right) \cdot d t
$$

Integrating the equation (12) gives the expression for the velocity $v$ of falling the crushing product through the workspace of the crusher:

$$
v=g \cdot\left(1-\frac{f \cdot(2-f \cdot \operatorname{tg} \alpha)}{f \cdot(2-f \cdot \operatorname{tg} \alpha)+\operatorname{tg} \alpha}\right) \cdot t+C
$$

For the initial conditions $\mathrm{t}=\mathrm{to}=0$, $\mathrm{v}=\mathrm{vo}=0$, and from the equation (13), it follows that the integration constant $\mathrm{C}=0$, and the final expression for the velocity rate of the crushed product through the workspace of the jaw crusher is:

$$
v=g \cdot\left(1-\frac{f \cdot(2-f \cdot \operatorname{tg} \alpha)}{f \cdot(2-f \cdot \operatorname{tg} \alpha)+\operatorname{tg} \alpha}\right) \cdot t,(\mathrm{~m} / \mathrm{s})
$$

The velocity of the piece $v$ can be expressed by the first derivative of the traveled path (the height $h$ - Fig.1) by the time $\mathrm{t}$, and the equation (14) gets the form:

$$
\frac{d h}{d t}=g \cdot\left(1-\frac{f \cdot(2-f \cdot \operatorname{tg} \alpha)}{f \cdot(2-f \cdot \operatorname{tg} \alpha)+\operatorname{tg} \alpha}\right) \cdot t
$$

respectively:

$$
d h=g \cdot\left(1-\frac{f \cdot(2-f \cdot \operatorname{tg} \alpha)}{f \cdot(2-f \cdot \operatorname{tg} \alpha)+\operatorname{tg} \alpha}\right) \cdot t \cdot d t
$$

Integrating the equation (16), the expression for the transmitted height $h$ is obtained by discharging the fragmentation product from the level $\mathrm{BB} 1$ to the level AA1, which is read as follows:

$$
h=\frac{g \cdot t^{2}}{2} \cdot\left(1-\frac{f \cdot(2-f \cdot \operatorname{tg} \alpha)}{f \cdot(2-f \cdot \operatorname{tg} \alpha)+\operatorname{tg} \alpha}\right)+C
$$

For the initial conditions $\mathrm{t}=$ to $=0$, $\mathrm{h}=\mathrm{ho}=0$, and from the equation (17), it follows that the integral constant $\mathrm{C}=0$, and the final expression for the transmitted height of decay the crushing product through the workspace of the crusher is read as follows:

$$
h=\frac{g \cdot t^{2}}{2} \cdot\left(1-\frac{f \cdot(2-f \cdot \operatorname{tg} \alpha)}{f \cdot(2-f \cdot \operatorname{tg} \alpha)+\operatorname{tg} \alpha}\right)
$$

From the equation (18), the necessary discharge time $\mathrm{t} 1$ is followed, which ensures that the crushed product that is below the level of BB1 comes out of the workspace during the empty stroke.

$$
t_{1}=\sqrt{\left[\frac{2 \cdot h}{g \cdot\left(1-\frac{f \cdot(2-f \cdot \operatorname{tg} \alpha)}{f \cdot(2-f \cdot \operatorname{tg} \alpha)+\operatorname{tg} \alpha}\right)}\right]}
$$

From the right triangle A1A2B1 (Fig. 1), it follows that:

$$
h=e / \operatorname{tg} \alpha
$$

Changing the expression for $\mathrm{h}$ from the equation (20) to the equation (19), it is obtained:

$$
t_{1}=\sqrt{\left\{\frac{2 \cdot e}{\left[g \cdot \operatorname{tg} \alpha \cdot\left(1-\frac{f \cdot(2-f \cdot \operatorname{tg} \alpha)}{f \cdot(2-f \cdot \operatorname{tg} \alpha)+\operatorname{tg} \alpha}\right)\right.}\right\}}
$$

The time $t_{2}$ of the empty stroke of the crusher, that is, the discharge time of fragmentation product is equal to the half-time of revolution of the crusher eccentric shaft: 


$$
t_{2}=60 /(2 \cdot n)
$$

where: $n$ is the number of revolutions, (Rpm)

Optimal speed of the eccentric shaft follows from the equality of time:

$$
t_{2}=t_{1}
$$

respectively:

$$
\frac{30}{n_{0}}=\sqrt{\frac{2 \cdot e}{g \cdot \operatorname{tg} \alpha \cdot\left(1-\frac{f \cdot(2-f \cdot \operatorname{tg} \alpha)}{f \cdot(2-f \cdot \operatorname{tg} \alpha)+\operatorname{tg} \alpha}\right.}}
$$

From where it follows that:

$$
n_{0}=30 \cdot \sqrt{\frac{g \cdot \operatorname{tg} \alpha}{2 \cdot e} \cdot\left[1-\frac{f \cdot(2-f \cdot \operatorname{tg} \alpha)}{f \cdot(2-f \cdot \operatorname{tg} \alpha)+\operatorname{tg} \alpha}\right]}
$$
(Rpm)

$\mathrm{n}_{0^{-}}$optimum speed of eccentric shaft,

$\mathrm{g}$ - acceleration due to the gravity, $\left(\mathrm{m} / \mathrm{s}^{2}\right)$

$\alpha$ - crusher working angle, $\left({ }^{\circ}\right)$

$\mathrm{e}$ - movement of the moving jaw at the level of the discharge opening $(\mathrm{m})$
For the conventional gripping angle of the abrasive crushers, $\alpha=22^{\circ}$, and the friction coefficient, $f=0.3$ (Fig. 3), a comparative graphic representation the change in the number of shaft rotations, in the function of the moving jaw at the level of the discharge opening, is given, according to the equations (1), (2), (25), and the crusher manufacturer Metso. Fig. 3 shows that the catalog values for the number of turns of the eccentric shaft, depending on the movement of the moving jaw, are found between the curves described by the equations (2) and (25).

It should be noticed that the values for throwing the moving jaw are calculated by the equation (26)[3], and based on catalog data [4], related to the number of revolutions and the size of discharge with:

$$
e=7+0.1 \cdot b_{1}(\mathrm{~mm})
$$

$\mathrm{b}_{1}$ - minimum width of a discharge opening of the jaw, (mm)

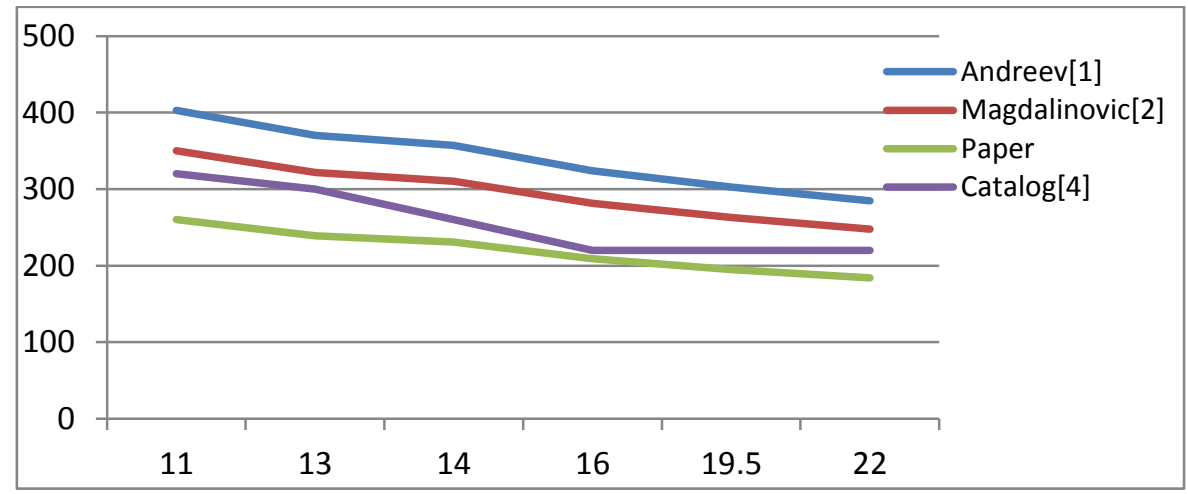

Fig. 3 Graphic view the number of revolutions (Rpm) depending on $t$ hrowing the moving jaw ( $\mathrm{mm}$ )

\section{CONCLUSION}

Having in mind the geometry of the workspace of the jaw crushers with the free movement of the moving jaw, and the obviously resistance the frictional force to the moving and fixed jaw when the crus- hing product is discharged, the optimum speed of the crusher eccentric shaft can be determined according to the formula (25), defined in this paper. 


\section{REFERENCES}

[1] Andreev S. A., Zverevič V. V. i Perov V.A., Droblenie, izmeljčenie i grohočenie poleznyh iskopaemyh, Nedra, Moskva, 1966 (in Russian)

[2] Magdalinović N., Theoretically Optimal Number of Revolutions of the Eccentric Axis of the Jaw Crushers with a Simple Motion of the Moving Jaw. Proceedings XXV, Technical Faculty and Copper Institute Bor, 1980/81, pp. 149-155 (in Serbian)

[3] M. Plavšić, Construction Machines, 1990. pp. 337 (in Serbian)

[4] Metso Minerals, Crushing and Screening Handbook, 2007 